\title{
Grafting of Neonatal Marmoset Monkey Testicular Single-Cell Suspensions into Immunodeficient Mice Leads to ex situ Testicular Cord Neomorphogenesis
}

\author{
Nelia Aeckerle $^{\mathrm{a}}$ Ralf Dressel ${ }^{\mathrm{b}}$ Rüdiger Behr ${ }^{\mathrm{a}}$

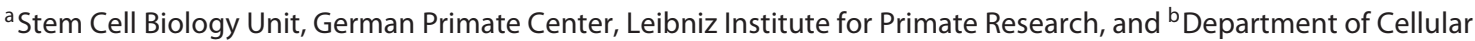 \\ and Molecular Immunology, University Medical Center Göttingen, Göttingen, Germany
}

\author{
Key Words \\ Germ cells $\cdot$ Non-human primate $\cdot$ Pluripotency $\cdot$ Sertoli \\ cell · Testicular morphogenesis
}

\begin{abstract}
Single-cell suspensions derived from immature rodent and ungulate testes can reconstitute testicular cords upon grafting into immunodeficient mice. In the present study, neonatal common marmoset monkey (Callithrix jacchus) testes were digested to a single-cell suspension, which was transplanted subcutaneously into immunodeficient mice. After 9 or 18 weeks of incubation, the derivatives of the grafted single-cell suspensions were retrieved and analyzed histologically and immunohistochemically. Three of 4 (75\%) neonatal grafts exhibited reconstituted seminiferous cords strongly resembling seminiferous cords of the intact neonatal testis. The cords consisted of Sertoli cells, germ cells and peritubular myoid cells, which was confirmed by immunohistochemical marker analysis. Three-dimensional reconstruction models of the grafts revealed elongated tubules. Some of the tubules were branched, which occurs also in vivo, as we show here for the marmoset monkey. Importantly, no teratoma formation by immature pluripotency factor-expressing germ cells was observed. In summary, the reconstituted testicular cords were almost indistinguishable from the cords formed in situ, thereby impressively demonstrating a very
\end{abstract}

high reconstructive potential of a single-cell suspension obtained from the neonatal marmoset monkey testis. To our knowledge, this is the first study demonstrating testicular cord neomorphogenesis for a primate species ex situ.

(c) 2013 S. Karger AG, Basel

\section{Introduction}

Germ cells transmit the genetic information from one generation to the next. During male adulthood, spermatogonial stem cells preserve the male germ lineage. Stem cells are located in a specialized environment, the stem cell niche, which controls their proliferation and dif-

\section{Abbreviations used in this paper}

AMH anti-müllerian hormone

DMEM Dulbecco's modified Eagle's medium

F-12 Ham's F-12 nutrient mixture

HRP horseradish peroxidase

MAGE-A4 melanoma-associated antigen 4

NB new born

NHP non-human primate

PGP protein gene product

SALL4 Sal-like protein 4

a-SMA $\quad$-smooth muscle actin

\begin{tabular}{ll}
\hline KARGER & $\begin{array}{l}\text { ○ 2013 S. Karger AG, Basel } \\
1422-6405 / 13 / 1983-0209 \$ 38.00 / 0 \quad \text { Karger } \\
\text { E-Mail karger@karger.com }\end{array}$ \\
www.karger.com/cto & $\begin{array}{l}\text { This is an Open Access article licensed under the terms of the } \\
\text { Creative Commons Attribution-NonCommercial 3.0 Un- } \\
\text { ported license (CC BY-NC) (www.karger.com/OA-license), } \\
\text { applicable to the online version of the article only. Distribu- } \\
\text { tion permitted for non-commercial purposes only. }\end{array}$
\end{tabular}

Dr. Rüdiger Behr

Stem Cell Biology Unit, German Primate Center

Kellnerweg 4

DE-37077 Göttingen (Germany)

E-Mail rbehr@dpz.eu 
ferentiation. Therefore, in the testes, the accurate spatial arrangement of the different cell types during embryogenesis is essential for the establishment of spermatogenesis in adulthood. During embryogenesis, an indifferent gonad arises, which is morphologically indistinguishable between males and females [Capel, 2000]. In the presence of SRY, the indifferent gonad develops into a testis. Histologically, testes and ovaries become distinguishable after formation of seminiferous cords in the testis. During cord formation, immature Sertoli cells aggregate with germ cells, differentiate and become polarized epithelial cells [Jost et al., 1981; Magre and Jost, 1991; Cupp and Skinner, 2005]. Concurrently, cells from the mesonephros migrate into the male gonad and surround the aggregating Sertoli and germ cells. It is assumed that these migrating cells become peritubular myoid cells and that this process is required for cord formation [Buehr et al., 1993; Tilmann and Capel, 1999]. A properly developed somatic environment is necessary to enable spermatogenesis during adulthood.

Researchers have long attempted to recapitulate the process of spermatogenesis in vitro [Kierszenbaum, 1994; Staub, 2001]. It was demonstrated that cocultured Sertoli cells and peritubular myoid cells isolated from pubertal rats aggregate and form structures resembling germ celldepleted tubules, while both Sertoli or peritubular cells alone were unable to form these structures [Tung and Fritz, 1980]. The rearrangement of tubular structures was also observed after transplantation of testicular cells in immunodeficient mice. This transplantation approach has been modified and evaluated further using testis cells from neonatal pigs [Honaramooz et al., 2007], rodents [Dufour et al., 2002; Gassei et al., 2006; Kita et al., 2007; Gassei et al., 2008], bovine [Zhang et al., 2008] and sheep [Arregui et al., 2008]. The reconstructed tubules consisted mostly of Sertoli cells and peritubular myoid cells, but occasionally germ cells were also observed. Spermatogenesis up to and beyond the level of round spermatids was obtained in reconstituted tissue from testis cell suspensions of immature pigs, sheep and embryonic or neonatal rats and mice [Honaramooz et al., 2007; Kita et al., 2007; Arregui et al., 2008]. In the mouse model, even fertilization-competent spermatids were obtained in reconstituted tubules [Kita et al., 2007].

In the neonatal marmoset testis (i.e. first few days after birth), the number of OCT4-positive germ cells is on average $12 \%$ of all germ cells, which are in the range between 0.12 and $0.56 \times 10^{6}$ cells [McKinnell et al., 2009]. Moreover, besides OCT4, many marmoset monkey gonocytes express the well-established key pluripotency factors
SOX2, NANOG, AP2 $\gamma$, Sal-like protein 4 (SALL4) and LIN28 [Mitchell et al., 2008; Albert et al., 2010; Aeckerle et al., 2012; Albert et al., 2012; Eildermann et al., 2012a], suggesting a developmental potential similar to pluripotent embryonic stem cells [Boyer et al., 2005]. Pluripotency of human and non-human primate (NHP) cells can be demonstrated by an assay technically identical to the approach used in this study, the teratoma formation assay: the test cells are injected into an immunodeficient mouse, where the cells can survive, proliferate and eventually differentiate for up to several weeks. Development of histologically normal endo-, meso- and ectodermal derivatives in this assay is the best indication of pluripotency currently available for human and NHP cells.

In pathological cases, immature germ cells may undergo immediate reprogramming to become a pluripotent embryonic germ cell, which is the origin of (intragonadal) teratomas or yolk sac tumors (type I germ cell tumors) [Oosterhuis and Looijenga, 2005]. However, to our knowledge, human or NHP gonocytes were never tested for their ability to form teratomas after removal from their natural lineage-committing environment and subsequent transplantation into immunodeficient mice. Therefore, in addition to the reconstructive potential of isolated cells from the NHP testis, we were also interested in whether pluripotency factor-expressing gonocytes were able to form teratoma under the experimental conditions used in this study.

We show here for the first time testicular cord reconstitution for an NHP after full enzymatic dissociation of the testis to a single-cell suspension. Reconstituted cords were able to maintain germ cells for at least 18 weeks. They also exhibited branching, which we document here, to our knowledge, also for the first time for NHP cord (re)constitution. In contrast to these novel findings regarding primate testis cord development, we obtained no evidence of a teratogenic potential of NHP neonatal gonocytes.

\section{Materials and Methods}

Marmoset Monkey Testis Tissue Samples

This study was performed in strict accordance with the German Animal Protection Law. All surgery was performed under anesthesia, and every effort was made to minimize suffering. Animals were housed according to the standard German Primate Center practice for common marmoset monkeys. For castration, animals were deeply anesthetized with an intramuscular injection of $0.5 \mathrm{ml} / \mathrm{kg}$ body weight of Göttinger mixture II (50 mg/ml ketamine, $10 \mathrm{mg}$ / $\mathrm{ml}$ xylazine and $10 \mathrm{mg} / \mathrm{ml}$ atropine) and $0.05 \mathrm{ml} / \mathrm{kg}$ body weight diazepam into the quadriceps femoris muscle. At this dose rate, the 


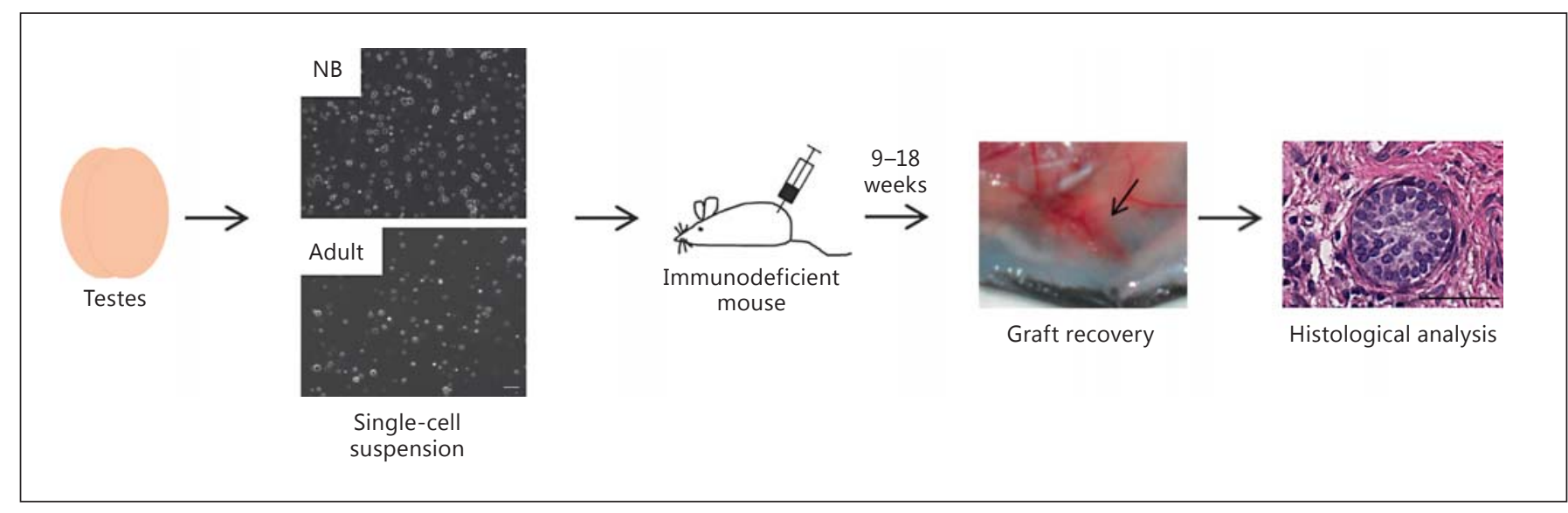

Fig. 1. Study design. Testes from marmoset monkeys of various ages were enzymatically digested to single cells. These single-cell suspensions were mixed 1:1 (vol/vol) with Matrigel and injected subcutaneously into an immunodeficient mouse. After incubation for 9 or 18 weeks, the grafts were recovered and prepared for histological and immunohistochemical analysis. Bar $=50 \mu \mathrm{m}$.

duration of anesthesia was usually $30-45$ min. For euthanasia of neonatal and juvenile monkeys, $0.2 \mathrm{ml}$ of Narcoren ${ }^{\circledR}$ were injected intraperitoneally. Nine marmoset monkey testes were used for the grafting experiments (the license number for adult testis retrieval was AZ11/0395). Neonatal and juvenile testes were obtained from animals that had to be killed due to animal husbandry reasons (inability of the mother to feed 3 neonates; no license necessary).

Derivation of a Single-Cell Suspension and Injection of Cells

Testes from 6 neonatal (1-2 days old, i.e. containing pluripotency marker-expressing germ cells), one 4-month-old and 2 adult (3.5-year-old) marmoset monkeys were used for cell preparation. A single-cell suspension was obtained using enzymatic digestion and subsequent filtering. In brief, testes were mechanically decapsulated and the seminiferous tubules were digested with $1 \mathrm{mg} / \mathrm{ml}$ collagenase I (Sigma, catalog No. C-2674), $1 \mathrm{mg} / \mathrm{ml}$ hyaluronidase (H-3506; Sigma) and 15 U/ml DNase I (Sigma, catalog No. D4263) in Dulbecco's modified Eagle's medium (DMEM; Gibco, catalog No. 31966021)/Ham's F-12 nutrient mixture (F-12; Gibco, catalog No. $31765027 ; 1: 1)$ under mild rotation at $37^{\circ} \mathrm{C}$ with pipetting up and down every 5-10 min until a single-cell suspension was achieved after $30-45 \mathrm{~min}$. The cell suspension was filtered through a $70-\mu \mathrm{m}$ mesh to assure that no tubule fragments remained. The single cells were washed with DMEM/F-12 supplemented with $10 \%$ FBS, Pen/Strep and AmpB; $4 \times 10^{5}$ to $6 \times 10^{6}$ cells were resuspended in $100 \mu \mathrm{l}$ DMEM/F-12 and mixed 1:1 (vol.) with Matrigel (BD Biosciences, catalog No. 356231). The fresh marmoset testicular cells were kept on ice prior to transplantation. Transplantation was performed within $1 \mathrm{~h}$. Images of single-cell suspension were taken on a Zeiss Axio Observer Z1 microscope.

\section{Grafting Procedure and Graft Recovery}

Immunodeficient adult RAG2 ${ }^{-/-} \gamma \mathrm{c}^{-/-}$or SCID (C.B-17/Ztmscid) mice (males and females) housed in the central facility for animal experimentation at the University Medical Center Göttingen served as hosts for xenografting. The license number for trans- plantation of cells into mice was 33.42502-04-113/09. SCID mice were used in 2 cases when due to the timing of the marmoset castrations no $\mathrm{RAG}^{-/-} \gamma \mathrm{c}^{-/-}$recipients were available. In contrast to $\mathrm{RAG}^{-/-} \gamma \mathrm{c}^{-/-}$mice, SCID mice have natural killer cells, but both strains are widely used in pluripotency assays and the presence of natural killer cells might delay but not prevent teratoma growth after injection of pluripotent stem cells [Dressel, 2011]. For grafting, $100 \mu \mathrm{l} \mathrm{DMEM} / \mathrm{F} 12$ containing $4 \times 10^{5}$ to $6 \times 10^{6}$ marmoset testicular cells were mixed 1:1 with Matrigel. Extracellular matrix gel was co-injected because of its ability to support cord formation in a previous report [Hadley et al., 1985]. The resulting solution was injected subcutaneously in the left groin region of the host mouse using a 1.25-inch injection needle. The contralateral side served as control: $200 \mu \mathrm{l}$ DMEM/F-12 without cells mixed with Matrigel (1:1) were injected. Grafts were allowed to develop for 9 or 18 weeks. An overview of the study design is given in figure 1 . The recipient mice were palpated twice weekly to check for tumor formation.

For graft retrieval, recipient mice were killed by cervical dislocation. The ventral skin of the mouse was removed and grafts were located on the interior surface of the skin. Grafts were excised and fixed in Bouin's fixative overnight at room temperature followed by several washes with $70 \%$ ethanol. Tissues were routinely embedded in paraffin, sectioned at $5 \mu \mathrm{m}$ and stained with hematoxylin-eosin for routine histological analyses.

\section{Immunohistochemistry of Tissue Sections}

For immunohistochemical staining, tissue sections were deparaffinized, rehydrated and an antigen retrieval step was performed by microwaving the sections in $10 \mathrm{mM}$ citrate buffer for $10 \mathrm{~min}$. Endogenous peroxidase was inhibited by incubation with a peroxidase blocking reagent (DakoCytomation, Carpinteria, Calif., USA; LSAB+ system-HRP, K0679). Antibody specifications and dilutions are given in table 1 . All incubation steps were done in a humid chamber and incubations with the primary antibody were performed overnight at $4{ }^{\circ} \mathrm{C}$. The DakoCytomation Universal $\mathrm{LSAB}+$ kit including biotinylated secondary antibody polymer and 
Table 1. Antibodies used in this study

\begin{tabular}{lllll}
\hline Antigen & Source & Catalog No. & Host & Dilution \\
\hline a-SMA & Sigma & A2547 & mouse & $1: 1,000$ \\
LIN28A & Cell Signaling & $3978 S$ & rabbit & $1: 70$ \\
MAGE-A4 & Giulio C. Spagnoli & & mouse & $1: 25$ \\
AMH & Santa Cruz & sc-6886 & goat & $1: 100$ \\
OCT4A & Cell Signaling & 2890 & rabbit & $1: 100$ \\
PGP9.5 & DakoCytomation & Z 5116 & rabbit & $1: 500$ \\
SALL4 & Abcam & ab57577 & mouse & $1: 200$ \\
SOX9 & Millipore & MAB5535 & rabbit & $1: 1,000$ \\
VASA & R\&D Systems & AF2030 & goat & $1: 100$ \\
Goat IgG isotype control & Antibodies-online & ABIN 376825 & goat & $1: 2,500$ \\
Mouse IgG isotype control & Vector & I-1000 & mouse & $1: 100$ \\
Rabbit IgG isotype control & Antibodies-online & ABIN 376827 & rabbit & $1: 2,500$ \\
\hline
\end{tabular}

horseradish peroxidase (HRP)-conjugated streptavidin was employed for the detection of bound primary antibody. 3,3'-Diaminobenzidine chromogen was used as substrate for HRP and Mayer's hematoxylin as counterstain. Control stainings were carried out using suitable nonspecific IgG instead of the specific antibody at the same protein concentration. Pictures were taken using a Zeiss microscope and the Nuance ${ }^{\mathrm{TM}}$ multispectral camera.

\section{Preparation of Seminiferous Tubules}

Pictures of seminiferous tubules were taken after decapsulation of the testes and enzymatic removal of the interstitial cells using $1 \mathrm{mg} / \mathrm{ml}$ collagenase I (Sigma, catalog No. C-2674) and $15 \mathrm{U} / \mathrm{ml}$ DNase I (Sigma, catalog No. D4263) in DMEM/F-12 (1:1). Pictures of the tubules were taken using a stereomicroscope (Discovery.V8 SteREO; Zeiss).

\section{D Model of the Reconstructed Tubules}

To construct a 3D model of the rearranged tubules we used the software Amira. With this software, the pictures of 29 adjacent sections were aligned. For construction of the model, some information on the voxel (3D pixel) size is needed. Since every section of the paraffin block is $5 \mu \mathrm{m}$ thick and $1 \mu \mathrm{m}$ of the picture correlates to 1 pixel, the voxel size was defined as $1 \times 1 \times 5$ pixels. To reduce the amount of data needed for the calculation, the color of the pictures was reduced to a gray scale. With the segmentation editor, the outlines of all tubules were marked. Based on this information, the software was able to calculate the surface of the tubules. Since the display of all tubules included in the graft was confusing, only few selected tubules are shown in the 3D model.

\section{Results}

\section{General Observations}

During the incubation period of the injected cells in the host mice, no tumors were palpable and no other adverse effects of the cell injections became obvious.
Tissue Digestion Results in Single-Cell Suspensions

Single-cell suspensions were obtained from marmoset monkey testes by enzymatic tissue digestion using collagenase, hyaluronidase and DNase. Completeness of the tissue disaggregation was confirmed microscopically after filtration of cell suspensions through a $70-\mu \mathrm{m}$ nylon mesh (fig. 1). Occasionally, few cells remained connected, but no tubular fragments were observed.

\section{Histological Analysis of the Grafts}

Derivatives of the transplanted cells from neonatal testes were found in 4 recipients (in total 4 recipients were successfully injected; $100 \%$ graft recovery). Three of 4 (75\%; table 2) of these xenografts from neonatal testis cells contained tubular structures strongly resembling seminiferous tubules of the neonatal marmoset monkey (fig. 2). Tubular structures occurred irrespective of the sex of the recipient mouse (table 2). Pieces of Matrigel were detected in the tissue surrounding the tubules (fig. 2c), which were distinguishable by their pink appearance after hematoxylin-eosin staining (marked with an asterisk).

Comparison of grafts after 9 or 18 weeks of incubation in the host mice revealed some differences. Figure $2 \mathrm{a}, \mathrm{b}$ shows tubules developed in a graft within 9 weeks. These tubules demonstrate almost no (fig. 2a) or only partial (fig. 2b) enclosure in peritubular myoid cells, which is reflected by the incomplete anti- $\alpha$-smooth muscle actin (SMA) staining surrounding the forming tubules. In some developing tubules, aggregation of putative Sertoli cells is visible while a clear and well-structured epithelial layer is not visible (fig. 2a). In contrast, more developed tubules exhibit formation of a well-structured polar epithelium in the tubules (fig. 2b). The more the tubules became enclosed 
Table 2. Overview of the grafting experiments performed in this study

\begin{tabular}{|c|c|c|c|c|c|c|}
\hline $\begin{array}{l}\text { Recipient } \\
\text { mouse } \\
\text { No. }\end{array}$ & $\begin{array}{l}\text { Age of the } \\
\text { donor marmoset }\end{array}$ & $\begin{array}{l}\text { Cells grafted, } \\
\mathrm{n}\end{array}$ & Host mouse & $\begin{array}{l}\text { Incubation } \\
\text { time, weeks }\end{array}$ & Teratoma & $\begin{array}{l}\text { Graft with } \\
\text { tubular } \\
\text { structures }\end{array}$ \\
\hline 1 & neonatal (2 animals) & $6 \times 10^{6}$ & $\mathrm{RAG}^{-/-} \gamma \mathrm{c}^{-/-}$female & 18 & no & yes \\
\hline 2 & neonatal & $2.5 \times 10^{6}$ & $\mathrm{RAG}^{-/-} \gamma \mathrm{c}^{-/-}$male & 9 & no & yes \\
\hline 3 & neonatal & $4 \times 10^{5}$ & $\mathrm{RAG}^{-/-} \gamma \mathrm{c}^{-/-}$male & 18 & no & yes \\
\hline 4 & neonatal & $1.9 \times 10^{6}$ & $\mathrm{RAG}^{-/-} \gamma \mathrm{c}^{-/-}$male & 9 & no & no \\
\hline 5 & juvenile & $1.2 \times 10^{6}$ & $\mathrm{RAG}^{-/-} \gamma \mathrm{c}^{-/-}$female & 19 & no & no \\
\hline 6 & adult & $3 \times 10^{6}$ & SCID female & 9 & no & no \\
\hline 7 & adult & $3 \times 10^{6}$ & SCID male & 9 & no & no \\
\hline
\end{tabular}

by peritubular myoid cells, the more mature they appear in their tissue architecture. This corresponds to normal tubule development in the testis. Figure $2 \mathrm{c}-\mathrm{e}$ depicts tubules developed for 18 weeks. Histological appearance and tubule boundaries are more prominent. Tubules exhibit Sertoli cells, a basal membrane and surrounding cells with the typical flat morphology of peritubular myoid cells (fig. 2e). None of the tubules reconstituted in the grafts showed a central lumen. This is in agreement with the lack of a lumen in the native marmoset testis until puberty (fig. 3). Pieces of Matrigel were found inside the grafts (fig. 2c: asterisk). The tissues collected after control injection of DMEM/F12 mixed with Matrigel without cells revealed the presence of Matrigel in the subcutaneous adipose tissue of the host mouse. Apart from the Matrigel pieces, we did not observe any additional histological structure which does not occur in normal mice (data not shown).

Analysis of injection sites of older donor (pubertal and adult) tissue revealed the presence of Matrigel in the subcutaneous adipose tissue of the host mouse. This indicates that we analyzed the injection site. However, no cells in the recovered tissue could clearly be traced back to the donor cells, and formation of tubular structures was absent (data not shown).

Histological analysis of the recovered tissue (fig. 2c) revealed that no tumor with the histological features of a teratoma, i.e. histologically mature derivatives of the three embryonic germ layers (ectoderm, mesoderm and endoderm) developed after injection of testicular cells from neonatal (4 recipients), juvenile (1 recipient) or adult ( 2 recipients) animals (table 2 ).

\section{Immunohistochemical Marker Analysis of the Graft Tissue}

To investigate which cell types contribute to seminiferous tubule formation, we performed immunohisto- chemistry with established markers for different cell types present in the donor tissue (fig. 3).

Anti-müllerian hormone (AMH) is a cytoplasmic marker of immature Sertoli cells in human as well as mouse testes [Tran et al., 1987; Behringer, 1995]. This marker has also been shown to be valid in the marmoset monkey testis [Mitchell et al., 2008; Albert et al., 2012, own unpubl. data]. The testis-determining SOX9 gene is a downstream transcription factor of SRY and essential for Sertoli cell specification. In the testis, its expression is restricted to Sertoli cells of all developmental stages, including terminally differentiated Sertoli cells. Its localization is nuclear. The expression pattern of SOX9 is conserved among diverse vertebrate species, which suggests an evolutionary conserved role [Morais da Silva et al., 1996].

As a marker of peritubular myoid cells, we used $\alpha$-SMA. It is known to be present in smooth muscle cells of blood vessels and in testicular peritubular myoid cells [Tung and Fritz, 1990; Dufour et al., 2002].

VASA (DDX4), LIN28, melanoma-associated antigen 4 (MAGE-A4), SALL4 and protein gene product (PGP) 9.5 were used as germ cell markers [Tokunaga et al., 1999; Castrillon et al., 2000; Aubry et al., 2001; Aeckerle et al., 2012; Eildermann et al., 2012a]. This marker panel detects premeiotic (VASA, LIN28, MAGE-A4, SALL4 and PGP9.5), meiotic (VASA and MAGE-A4) and postmeiotic (VASA) germ cells in mammalian testes.

OCT4A was used as marker for pluripotent and immature germ cells. Previously, OCT4 expression was noted in neonatal marmoset testis [Mitchell et al., 2008]. Our data (this study) generated with a novel OCT4A-specific antibody different from those analyzed previously [Warthemann et al., 2012] support the studies on OCT4 expression in marmoset gonocytes published by other groups. 
Fig. 2. Histological analysis of the grafts. Tubular structures developed inside the grafts, showing very similar morphology to intact testicular tissue of neonatal marmoset monkeys. a, b Graft after 9 weeks of incubation in the host mouse. Anti- $\alpha$-SMA staining reveals that the grafts become surrounded by peritubular myoid cells during development. Some tubules showed no (a) and others only partial enclosure by peritubular myoid cells (b). Enclosure of the developed tubules seems to be associated with maturity of the tubules. The more a tubule is surrounded by peritubular myoid cells, the more organized are the cells within the tubule. b The tubule exhibits an obvious morphological polarity of the cells inside. c-e Graft developed within 18 weeks after injection of neonatal marmoset testicular cells into an immunodeficient host mouse. c Representative section of the graft. The tissue containing the reaggregated tubules is surrounded by adipose tissue of the host mouse. d, e Different magnifications of mature tubules which are almost indistinguishable from those in intact neonatal testes. They exhibit Sertoli cells, a basal membrane and surrounding cells with the typical flat morphology of peritubular myoid cells. None of the tubules reconstituted in the grafts showed a central lumen, which is in agreement with the lack of a lumen in the native marmoset testis until puberty. Pink areas show remaining Matrigel (*). a, b, d, e $\operatorname{Bar}=50 \mu \mathrm{m}$. c Bar $=100 \mu \mathrm{m}$.
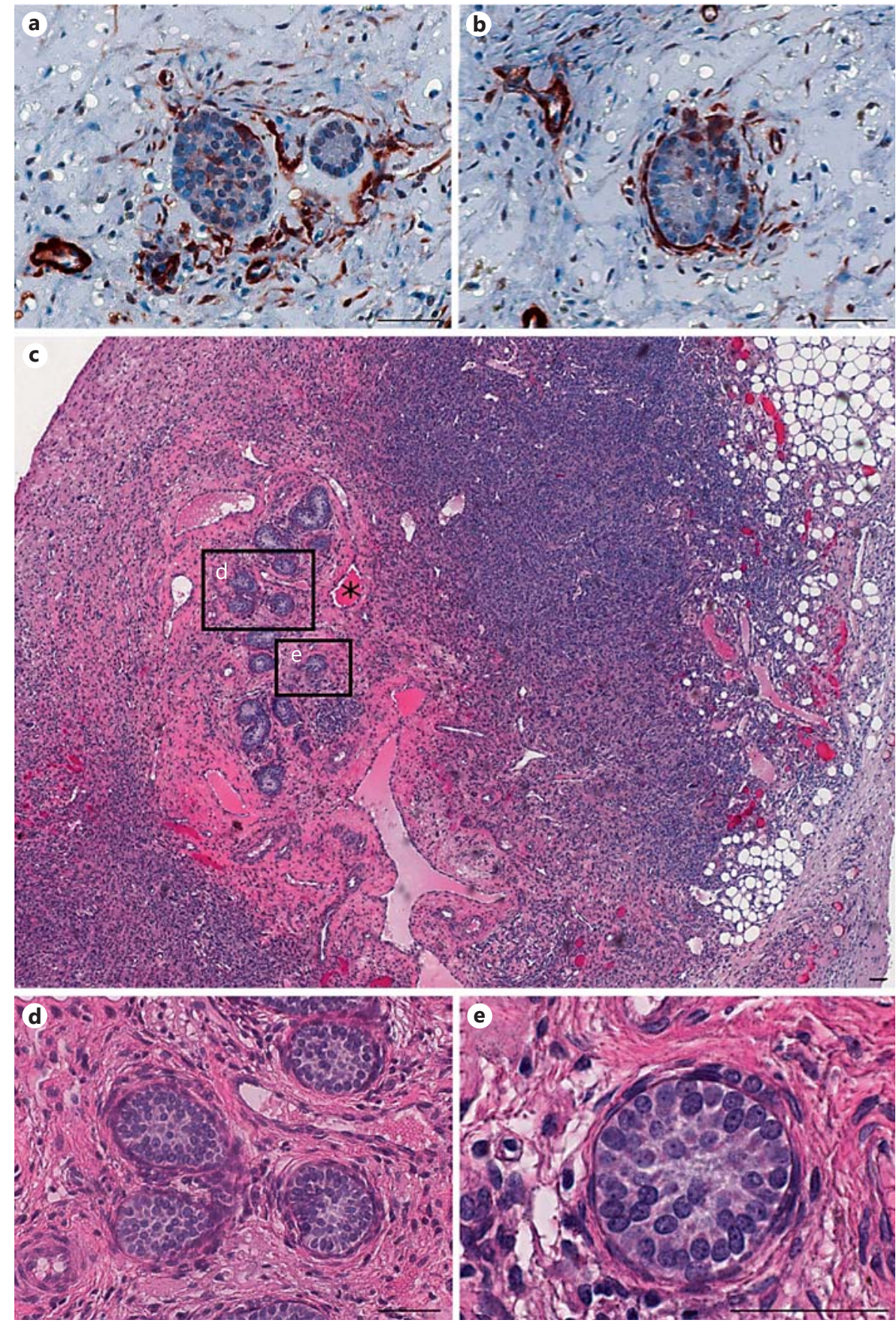

The donor tissue from neonatal testes used for the teratoma formation assay contained somatic cells, such as immature (i.e. not yet terminally differentiated and still proliferating) peritubular myoid ( $(\mathrm{S}-\mathrm{SMA}+)$ and immature Sertoli cells (AMH+ and SOX9+). The prevalent germ cell type in the neonatal donor tissue was the gonocyte (LIN28+, PGP9.5+, MAGE-A4+, VASA+ and
SALL4+), which represents the developmental stage between the primordial germ cells and the spermatogonial stem cells (fig. 3 ).

AMH immunostaining of the grafts revealed the presence of immature Sertoli cells in the cords. AMH was present in the cytoplasm of Sertoli cells for at least 18 weeks. This pattern is similar to AMH expression in pre- 


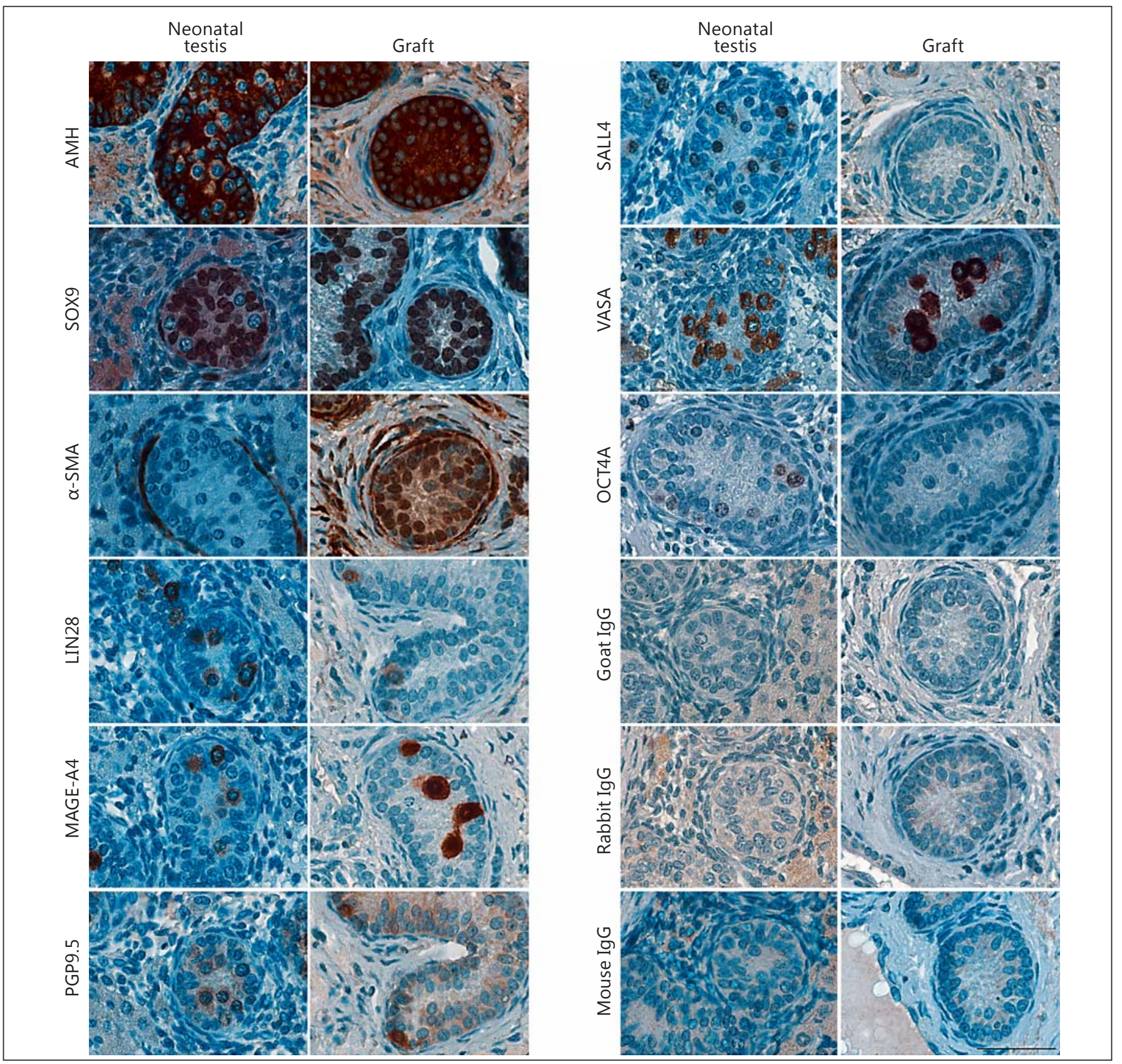

Fig. 3. Histological and immunohistochemical analysis of donor tissue and grafts. Reconstituted tubules in a graft after 18 weeks compared to intact neonatal testicular tissue. The testes of neonatal marmoset monkeys consist of seminiferous tubules and an interstitial compartment. The tubules contain Sertoli cells which express AMH and SOX9, and gonocytes which express LIN28, PGP9.5, MAGE-A4, VASA, OCT4 and SALL4. The tubules are surrounded by myoid peritubular cells which express $\alpha$-SMA. The Leydig cells are located in the interstitial compartment. The tubules reconstituted in the grafts exhibit marker expression very similar to that in neonatal testes. The reconstituted tubules mainly consist of Sertoli cells, which is indicated by AMH and SOX9 expression of the cells. The number of Sertoli cells per cross section in the reconstituted tubules is comparable to that in normal testis tissue. The anti-a-SMA staining in the grafts was not restricted to peritubular cells. Many a-SMA+ cells are located in the interstitial compartment. Surprisingly, a-SMA signals were also obtained in nuclei of putative Sertoli cells inside the reconstituted tubules, which express AMH and SOX9 and exhibit the characteristic morphology of Sertoli cells. Germ cells are evidenced in the reconstituted tubules by the expression of VASA, MAGE-A4, PGP9.5 and LIN28. The number of germ cells present in the reconstituted tubules appeared lower than in intact testicular tissue. SALL4 and OCT4 expression was undetectable in all reconstituted tubules analyzed. For controls, unspecific IgG isotype controls were used. They show no specific signal. Bar $=50 \mu \mathrm{m}$.
Primate Testicular Cord

Neomorphogenesis ex situ
Cells Tissues Organs 2013;198:209-220 DOI: $10.1159 / 000355339$ 

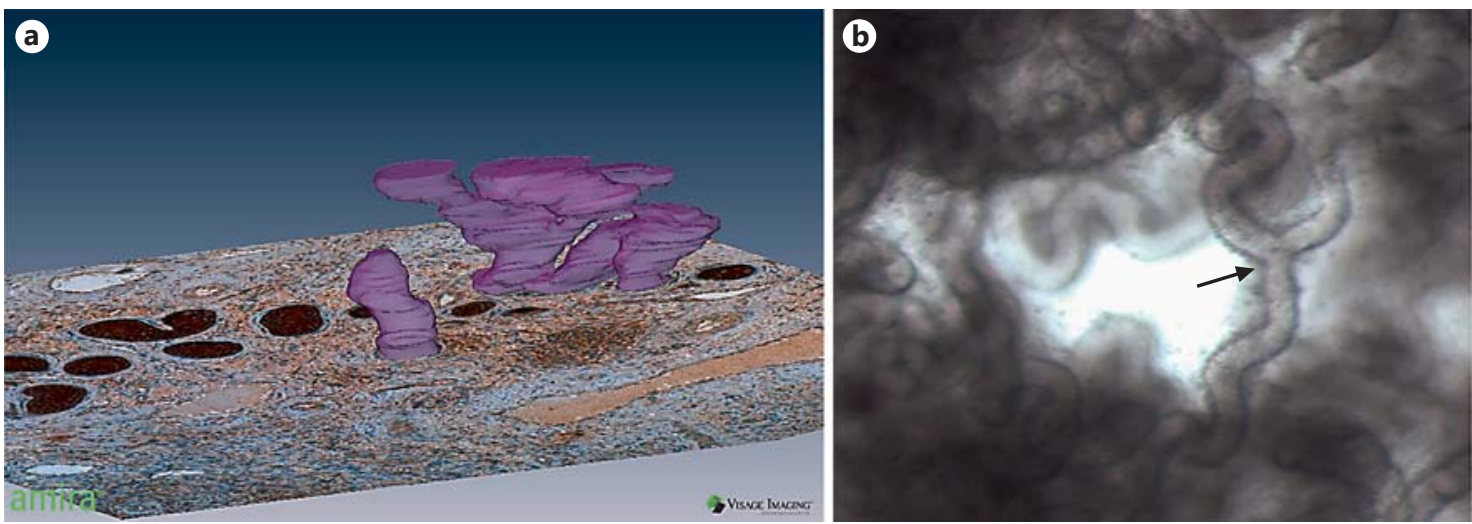

Fig. 4. Construction of a 3D model of the reconstructed tubules. a We used 29 adjacent sections for construction of the model. Since every paraffin section is $5 \mu \mathrm{m}$ thick, the height of the model is 145 $\mu \mathrm{m}$. The generated 3D model showed spherical structures as well as elongated tubules. Some of the elongated tubules are branched.
Since the display of all tubules included in the graft may lead to confusion, only some selected tubules of the graft are shown. b Seminiferous tubules of a neonatal testis after removal of the interstitial tissue. Some tubules are branched (arrow). pubertal marmoset monkey testes, suggesting that the transplanted Sertoli cells maintained their cellular identity. Sertoli cells in the periphery of the tubules appear polarized with their nuclei aligned along the basal membrane of the epithelium. The identity of the Sertoli cells was further confirmed by SOX 9 expression. The specificity of the antibody for marmoset monkey SOX9 protein was corroborated by specific nuclear staining of pre-Sertoli cells in male gonadal primordia before the onset of sexual differentiation, while no staining was seen in gonadal primordia of female sibling embryos (data not shown). The peritubular myoid cells ( $\alpha-\mathrm{SMA}+$ ) were surrounding the tubules. However, Sertoli cell nuclei in the graft as well as cells in the tissue between the tubules were also $a-S M A+$. $a-S M A+$ cells were additionally detected surrounding newly formed blood vessels (fig. 2a, b), which was also observed in intact neonatal testicular tissue.

One of $3(33 \%)$ marmoset tissue grafts showing reconstituted tubules contained tubules with germ cells positive for VASA, LIN28, MAGE-A4 and PGP9.5 (fig. 3). VASA and MAGE-A4 exhibited stronger staining in the graft than neonatal testis. However, we are not able to discern whether this is due to biological differences in VASA and MAGE-A4 abundance or whether there are also technical factors, e.g. the grade of fixation, which may influence the staining intensity. One additional graft exhibited PGP9.5+ and MAGE-A4+ cells, but was negative for the other germ cell markers. In none of the reconstructed tubules, SALL4+ or OCT4A+ gonocytes were detectable. Control staining using the respective nonspecific IgG instead of the primary antibodies resulted in no staining. A comparison between neonatal testis and graft tissue (fig. 3) reveals that the morphology of the reconstructed tubules was almost indistinguishable from the appearance of normal testis tissue from neonatal marmoset monkeys. General tissue architecture appeared normal compared to neonatal testis cords. Some germ cells in the grafts were in a rather central position in the developing tubule, while other germ cells showed partial or even full contact with the basal lamina of the reconstructed epithelium. This suggests normal Sertoli-germ cell interaction. However, there was no indication (such as meiotic chromatin structure) that the surviving marmoset gonocytes further differentiated after injection. Their location within the epithelium and the cytoplasm/nucleus ratio in these cells identify them as gonocytes or (pre-) spermatogonia, which corresponds to the germ cell stages seen in situ. Marmoset monkeys exhibit a high Sertoli:germ cell ratio in the neonatal testis [Mitchell et al., 2008], which seems to be even higher in the graft. However, quantification of cell populations was not performed in this study.

\section{D Model of the Reconstructed Tubules}

In order to get an idea of the extension and 3D structure of the reconstituted seminiferous tubules, we constructed a 3D model derived from consecutive histological sections using the Amira software (fig. 4a). The generated 3D model showed spherical structures as well 
as elongated cords. Some of the reconstituted cords were branched, which is in accordance with the situation in vivo (fig. $4 \mathrm{~b}$, arrow). The height of the model is $145 \mu \mathrm{m}$.

\section{Discussion}

This study shows that cells from the postnatal NHP testis exhibit a remarkable reconstructive potential. The dispersed Sertoli cells realigned along a newly formed basement membrane and subsequently formed epithelium, while the peritubular myoid cells surrounded the polarized Sertoli cells forming distinct cords. The ability of isolated neonatal testis cells to recapitulate characteristic aspects of testicular morphogenesis appears to be initiated by interactions between Sertoli cells and peritubular myoid cells [Dufour et al., 2002]. One major difference between immature neonatal and juvenile or adult Sertoli cells is their proliferation rate. While neonatal Sertoli cells are highly proliferative, adult Sertoli cells are arrested in $\mathrm{G}_{0}$ phase [Sharpe et al., 2003]. This might be the major reason why only neonatal Sertoli cells formed reconstituted tubules [Watanabe et al., 2009]. However, two different Ki-67 antibodies, which specifically label proliferating cells, did not work on these Bouin-fixed marmoset monkey tissues. Therefore, we were not able to further elucidate if the tubules in the grafts developed due to reassembly of injected preexisting cells or if the tubules formed by proliferation of small clusters of proliferating cells or even a single proliferating Sertoli cell. Nevertheless, a high proliferation capability or other unknown characteristics of neonatal Sertoli cells appear to be necessary, since grafting of Sertoli cells from older donors (juvenile or adult) did not result in cord formation. This also indicates that only immature somatic cells are capable of reorganizing cord-like structures for NHP.

The grafted neonatal cells mimicked the testicular development in vivo: the myoid cells in the graft migrated and surrounded the aggregating Sertoli and germ cells. As the graft matured, the myoid cells were located close to Sertoli cell nuclei located in the basal part of the cells. Nine and 18 weeks after injection, well-reconstructed fragments of seminiferous cords almost indistinguishable from the normal ones in the neonatal testis developed. Sertoli cells, peritubular myoid cells and gonocytes expressed all markers (except for SALL4 and OCT4A in the case of germ cells) tested in our laboratory to determine the cellular identity of different cell types in the normal testis.

Primate Testicular Cord

Neomorphogenesis ex situ
The number of germ cells appeared to be relatively low in the grafts compared to natural cords, and not all reconstructed cords contained germ cells. We assume that this is due to the facts described in the following. Our unpublished experiments with cultured germ cells (gonocytes) showed that these cells are very vulnerable and vanish already after a few days in culture. Therefore, we assume that the disintegration of the testis before injection of the cell solution (which is the same procedure as for cell culture) is major stress for the cells leading to significant germ cell loss. Hence, we speculate that the single-cell solution available for tubulus reconstruction after injection does not represent the normal neonatal composition, i.e. the germ cells are underrepresented. This was also described for bovine cells [Honaramooz et al., 2007]. Furthermore, the Sertoli cells may exhibit a higher proliferation rate than germ cells, which leads to a dilution effect of the germ cells in an increasing Sertoli cell population after grafting.

It was evident that the Sertoli and peritubular myoid cells in the more mature grafts (18 weeks) were arranged strikingly similar to the seminiferous epithelial layer in neonatal marmoset monkey cords. The strong staining signal for $\alpha$-SMA in peritubular cells suggests that these cells possess mature, functional contractile elements. The antibody against $\alpha$-SMA detects only one specific band for marmoset $\alpha$-SMA in Western blot analysis of marmoset monkey testis [Eildermann and Behr, unpubl. data]. Interestingly, the detection of nuclear signals for $\alpha$-SMA within the cells of the reconstructed tubules is in accordance with the situation detected in 1 fetal marmoset gonad at GD95 [Aeckerle and Behr, unpubl. data]. If this represents any functionally significant condition remains to be determined.

The 3D model of the tubules in the graft showed spherical structures as well as elongated tubules. Some of the elongated tubules were branched. Branching of seminiferous tubules was previously reported for fetal and neonatal human testes [Hedinger and Weber, 1973], but it is generally a rarely described phenomenon. In this study, we detected tubular branching in reconstructed tubules as well as in the neonatal marmoset monkey testes. Thus, this indicates that, although destructed to a single-cell suspension, the testicular cells keep the inherent information to rebuild the complex histological 3D structure of a developing testicular seminiferous tubule consisting of at least two somatic cell types and germ cells. Previous studies reported cord formation at different transplantation sites, such as the renal subcapsular space, subcutaneous space, epididymal fat pad and omental pouch [Dufour et 
al., 2002], suggesting that information inherent in the cells within the graft rather than instructive signals from the environment directs the neomorphogenesis of the cord structures.

Although we found germ cells in some tubules, it is not clear whether the testicular cords in the grafts are functional. The readout of functionality might be sperm production. In this study, germ cell differentiation apparently did not occur probably due to one of the following reasons: (i) the endocrine milieu was inappropriate for spermatogenesis; (ii) the time was not sufficient for entry into meiosis since even in vivo spermatocytes do not appear at 18 weeks of age in the marmoset testis, and (iii) a functionally abnormal germ cell-Sertoli cell interaction. Although previous studies in the marmoset monkey model reported grafting of immature testicular tissue [Schlatt et al., 2002; Wistuba et al., 2004], so far no singlecell suspensions (including isolated pluripotency factorpositive germ cells removed from their natural niche) were grafted xenologously. Importantly, in testicular tissue grafts from marmosets spermatogenesis did not proceed beyond the spermatogonial stage, although the germ cells grafted were present in their complete histological niche. The reason for this might be the absence of exon 10 of the marmoset luteinizing hormone receptor gene [Gromoll et al., 2003; Muller et al., 2004], which renders the marmoset sensitive to choriongonadotropin, but insensitive to luteinizing hormone. Since mice do not express choriongonadotropin, the host endocrine environment probably could not support androgen production in the graft. This lack of androgen production results in poor spermatogenesis after grafting [Schlatt et al., 2002; Wistuba et al., 2004]. However, other species-specific physiological reasons are also conceivable to be responsible for the arrest of testicular development in marmoset testicular grafts [Wistuba et al., 2004]. The resolution of this blockade is necessary to analyze the functionality of the reorganized cells and would allow the establishment of an in vivo model for postnatal primate testicular development. It would also offer the scientifically interesting possibility to (genetically) manipulate the germ cells prior to grafting.

Marmoset monkey gonocytes express many markers characteristic of pluripotent embryonic stem cells, e.g. OCT4, NANOG, AP2 $\gamma$, SALL4 and LIN28. Moreover, it is accepted knowledge that teratomas arise from undifferentiated germ cells of the primordial germ cell or gonocyte/oogonia stage. Therefore, we hypothesized that neonatal marmoset monkey gonocytes may form teratomas. In parallel experiments to this study, we generated ter- atomas using marmoset monkey iPS cells in RAG2 $2^{-/-}$ $\mathrm{\gamma c}^{-/-}$mice [Debowski and Behr, unpubl. data]. However, in the present experimental setting and in the limited numbers of experiments we were able to perform, we did not observe any teratoma. We were also not able to detect OCT4A in germ cells of the graft or in any other cell surrounding the tubules. The lack of OCT4 in germ cells may reflect the normal development of germ cells during postnatal development during 9-18 weeks. However, altogether, our study suggests that NHP gonocytes are not highly teratogenic at birth. We cannot exclude that some soluble factors from the co-injected somatic cells or direct somatic cell-germ cell interactions keep the gonocytes in a non-pluripotent and non-teratogenic state. Nevertheless, it is conceivable that cultured human and NHP gonocyte- or spermatogonia-derived cells (if their culture and propagation are possible) may revert or dedifferentiate to a developmental state that is characterized by pluripotency, as it has been shown for the mouse [KanatsuShinohara et al., 2004; Guan et al., 2006]. Moreover, it would be interesting to purify marmoset monkey gonocytes to test their teratoma formation potential when separated from somatic cells. Unfortunately, to our knowledge, there is at present no useful marker for the specific enrichment of primate gonocytes available; all surface markers used previously and known to us are also expressed by testicular multipotent stromal cells [Eildermann et al., 2012b]. Hence, we were not able to efficiently enrich gonocytes (or even spermatogonia) from the neonatal or adult marmoset monkey testis, respectively [Eildermann et al., 2012b; Aeckerle and Behr, own unpubl. data]. Moreover, the very small size of the neonatal marmoset gonad $(7.4 \pm 2.99 \mathrm{mg} ; \mathrm{n}=35)$ prevents many approaches to purify and functionally characterize marmoset monkey gonocytes. Therefore, culture and significant propagation of these cells were so far impossible in our hands.

In summary, testicular cord-like structures almost indistinguishable from the normal testis cords were found upon xenografting of a single-cell suspension obtained from the neonatal NHP testis into mice. This impressively demonstrated the reconstructive potential of isolated testicular cells from the marmoset monkey and may represent a new system for the study of testicular morphogenesis and testis cell biology. Our study provides no evidence for a pluripotent and teratogenic potential of gonocytes from the neonatal marmoset monkey testis. 


\section{Acknowledgment}

This study was supported in part by BMBF (Bundesministerium für Bildung und Forschung) grant 01GN0809/10 entitled 'Pluripotent cells in primate testes' to R.B. and by the German Research Foundation by unrestricted grants within the Research Unit 'Germ Cell Potential' (FOR-BE 2296/6-2) to R.B., Jörg Gromoll and Stefan Schlatt.
We thank Angelina Berenson, Nicole Umland and Marion Seidel for excellent technical assistance and the Pathology Unit at the German Primate Center for support. N.A. is a PhD student of Biology at the Jacobs University Bremen. We gratefully acknowledge the support of Prof. Alexander Lerchl and Prof. Matthias Ullrich (Jacobs University Bremen).

\section{References}

Aeckerle, N., K. Eildermann, C. Drummer, J. Ehmcke, S. Schweyer, A. Lerchl, M. Bergmann, S. Kliesch, J. Gromoll, S. Schlatt, R. Behr (2012) The pluripotency factor LIN28 in monkey and human testes: a marker for spermatogonial stem cells? Mol Hum Reprod 18: $477-488$.

Albert, S., J. Ehmcke, J. Wistuba, K. Eildermann, R. Behr, S. Schlatt, J. Gromoll (2010) Germ cell dynamics in the testis of the postnatal common marmoset monkey (Callithrix jacchus). Reproduction 140: 733-742.

Albert, S., J. Wistuba, K. Eildermann, J. Ehmcke, S. Schlatt, J. Gromoll, N. Kossack (2012) Comparative marker analysis after isolation and culture of testicular cells from the immature marmoset. Cells Tissues Organs 196: 543-554.

Arregui, L., R. Rathi, S.O. Megee, A. Honaramooz, M. Gomendio, E.R. Roldan, I. Dobrinski (2008) Xenografting of sheep testis tissue and isolated cells as a model for preservation of genetic material from endangered ungulates. Reproduction 136: 85-93.

Aubry, F., A.P. Satie, N. Rioux-Leclercq, E. Rajpert-De Meyts, G.C. Spagnoli, P. Chomez, O. De Backer, B. Jegou, M. Samson (2001) MAGE-A4, a germ cell specific marker, is expressed differentially in testicular tumors. Cancer 92: 2778-2785.

Behringer, R.R. (1995) The müllerian inhibitor and mammalian sexual development. Philos Trans R Soc Lond Biol Sci 350: 285-288.

Boyer, L.A., T.I. Lee, M.F. Cole, S.E. Johnstone, S.S. Levine, J.P. Zucker, M.G. Guenther, R.M. Kumar, H.L. Murray, R.G. Jenner, D.K. Gifford, D.A. Melton, R. Jaenisch, R.A. Young (2005) Core transcriptional regulatory circuitry in human embryonic stem cells. Cell 122: 947-956.

Buehr, M., S. Gu, A. McLaren (1993) Mesonephric contribution to testis differentiation in the fetal mouse. Development 117: 273-281.

Capel, B. (2000) The battle of the sexes. Mech Dev 92: 89-103.

Castrillon, D.H., B.J. Quade, T.Y. Wang, C. Quigley, C.P. Crum (2000) The human VASA gene is specifically expressed in the germ cell lineage. Proc Natl Acad Sci USA 97: 9585-9590.
Cupp, A.S., M.K. Skinner (2005) Embryonic Sertoli cell differentiation; in Skinner, M.K., M.D. Griswold (eds): Sertoli Cell Biology. Amsterdam, Elsevier.

Dressel, R. (2011) Effects of histocompatibility and host immune responses on the tumorigenicity of pluripotent stem cells. Semin Immunopathol 33: 573-591.

Dufour, J.M., R.V. Rajotte, G.S. Korbutt (2002) Development of an in vivo model to study testicular morphogenesis. J Androl 23: 635-644.

Eildermann, K., N. Aeckerle, K. Debowski, M. Godmann, H. Christiansen, M. Heistermann, S. Schweyer, M. Bergmann, S. Kliesch, J. Gromoll, J. Ehmcke, S. Schlatt, R. Behr (2012a) Developmental expression of the pluripotency factor Sal-like protein 4 in the monkey, human and mouse testis: restriction to premeiotic germ cells. Cells Tissues Organs 196: 206-220.

Eildermann, K., J. Gromoll, R. Behr (2012b) Misleading and reliable markers to differentiate between primate testis-derived multipotent stromal cells and spermatogonia in culture. Hum Reprod 27: 1754-1767.

Gassei, K., J. Ehmcke, S. Schlatt (2008) Initiation of testicular tubulogenesis is controlled by neurotrophic tyrosine receptor kinases in a three-dimensional Sertoli cell aggregation assay. Reproduction 136: 459-469.

Gassei, K., S. Schlatt, J. Ehmcke (2006) De novo morphogenesis of seminiferous tubules from dissociated immature rat testicular cells in xenografts. J Androl 27: 611-618.

Gromoll, J., J. Wistuba, N. Terwort, M. Godmann, T. Muller, M. Simoni (2003) A new subclass of the luteinizing hormone/chorionic gonadotropin receptor lacking exon 10 messenger RNA in the New World monkey (Platyrrhini) lineage. Biol Reprod 69: 75-80.

Guan, K., K. Nayernia, L.S. Maier, S. Wagner, R. Dressel, J.H. Lee, J. Nolte, F. Wolf, M. Li, W. Engel, G. Hasenfuss (2006) Pluripotency of spermatogonial stem cells from adult mouse testis. Nature 440: 1199-1203.

Hadley, M.A., S.W. Byers, C.A. Suarez-Quian, H.K. Kleinman, M. Dym (1985) Extracellular matrix regulates Sertoli cell differentiation, testicular cord formation, and germ cell development in vitro. J Cell Biol 101: 15111522 .
Hedinger, C., E. Weber (1973) Zur Struktur des Tubulussystemes in menschlichen Hoden. Z Anat Entwickl Gesch 139: 217-226.

-Honaramooz, A., S.O. Megee, R. Rathi, I. Dobrinski (2007) Building a testis: formation of functional testis tissue after transplantation of isolated porcine (Sus scrofa) testis cells. Biol Reprod 76: 43-47.

Jost, A., S. Magre, R. Agelopoulou (1981) Early stages of testicular differentiation in the rat. Hum Genet 58: 59-63.

Kanatsu-Shinohara, M., K. Inoue, J. Lee, M. Yoshimoto, N. Ogonuki, H. Miki, S. Baba, T. Kato, Y. Kazuki, S. Toyokuni, M. Toyoshima, O. Niwa, M. Oshimura, T. Heike, T. Nakahata, F. Ishino, A. Ogura, T. Shinohara (2004) Generation of pluripotent stem cells from neonatal mouse testis. Cell 119: 1001-1012.

Kierszenbaum, A.L. (1994) Mammalian spermatogenesis in vivo and in vitro: a partnership of spermatogenic and somatic cell lineages. Endocr Rev 15: 116-134

Kita, K., T. Watanabe, K. Ohsaka, H. Hayashi, Y. Kubota, Y. Nagashima, I. Aoki, H. Taniguchi, T. Noce, K. Inoue, H. Miki, N. Ogonuki, H. Tanaka, A. Ogura, T. Ogawa (2007) Production of functional spermatids from mouse germline stem cells in ectopically reconstituted seminiferous tubules. Biol Reprod 76: 211-217.

- Magre, S., A. Jost (1991) Sertoli cells and testicular differentiation in the rat fetus. J Electron Microsc Tech 19: 172-188.

McKinnell, C., R.T. Mitchell, M. Walker, K. Morris, C.J. Kelnar, W.H. Wallace, R.M. Sharpe (2009) Effect of fetal or neonatal exposure to monobutyl phthalate (MBP) on testicular development and function in the marmoset. Hum Reprod 24: 2244-2254.

Mitchell, R.T., G. Cowan, K.D. Morris, R.A. Anderson, H.M. Fraser, K.J. McKenzie, W.H. Wallace, C.J. Kelnar, P.T. Saunders, R.M. Sharpe (2008) Germ cell differentiation in the marmoset (Callithrix jacchus) during fetal and neonatal life closely parallels that in the human. Hum Reprod 23: 2755-2765.

Morais da Silva, S., A. Hacker, V. Harley, P. Goodfellow, A. Swain, R. Lovell-Badge (1996) Sox9 expression during gonadal development implies a conserved role for the gene in testis differentiation in mammals and birds. Nat Genet 14: 62-68.
Primate Testicular Cord

Neomorphogenesis ex situ
Cells Tissues Organs 2013;198:209-220 DOI: $10.1159 / 000355339$ 
Muller, T., J. Gromoll, A.P. Simula, R. Norman, R. Sandhowe-Klaverkamp, M. Simoni (2004) The carboxyterminal peptide of chorionic gonadotropin facilitates activation of the marmoset LH receptor. Exp Clin Endocrinol Diabetes 112: 574-579.

Oosterhuis, J.W., L.H. Looijenga (2005) Testicular germ-cell tumours in a broader perspective. Nat Rev Cancer 5: 210-222.

Schlatt, S., S.S. Kim, R. Gosden (2002) Spermatogenesis and steroidogenesis in mouse, hamster and monkey testicular tissue after cryopreservation and heterotopic grafting to castrated hosts. Reproduction 124: 339-346.

-Sharpe, R.M., C. McKinnell, C. Kivlin, J.S. Fisher (2003) Proliferation and functional maturation of Sertoli cells, and their relevance to disorders of testis function in adulthood. Reproduction 125: 769-784.

-Staub, C. (2001) A century of research on mammalian male germ cell meiotic differentiation in vitro. J Androl 22: 911-926.
Tilmann, C., B. Capel (1999) Mesonephric cell migration induces testis cord formation and Sertoli cell differentiation in the mammalian gonad. Development 126: 2883-2890.

Tokunaga, Y., S. Imai, R. Torii, T. Maeda (1999) Cytoplasmic liberation of protein gene product 9.5 during the seasonal regulation of spermatogenesis in the monkey (Macaca fuscata). Endocrinology 140: 1875-1883.

Tran, D., J.Y. Picard, J. Campargue, N. Josso (1987) Immunocytochemical detection of anti-müllerian hormone in Sertoli cells of various mammalian species including human. J Histochem Cytochem 35: 733-743.

Tung, P.S., I.B. Fritz (1980) Interactions of Sertoli cells with myoid cells in vitro. Biol Reprod 23: 207-217.

Tung, P.S., I.B. Fritz (1990) Characterization of rat testicular peritubular myoid cells in culture: alpha-smooth muscle isoactin is a specific differentiation marker. Biol Reprod 42: 351-365.
Warthemann, R., K. Eildermann, K. Debowski, R. Behr (2012) False-positive antibody signals for the pluripotency factor OCT4A (POU5F1) in testis-derived cells may lead to erroneous data and misinterpretations. Mol Hum Reprod 18: 605-612.

Watanabe, T., H. Hayashi, K. Kita, Y. Kubota, T. Ogawa (2009) Ectopic porcine spermatogenesis in murine subcutis: tissue grafting versus cell-injection methods. Asian J Androl 11: 317-323.

Wistuba, J., M. Mundry, C.M. Luetjens, S. Schlatt (2004) Cografting of hamster (Phodopus sungorus) and marmoset (Callithrix jacchus) testicular tissues into nude mice does not overcome blockade of early spermatogenic differentiation in primate grafts. Biol Reprod 71: 2087-2091.

Zhang, Z., J. Hill, M. Holland, Y. Kurihara, K.L. Loveland (2008) Bovine Sertoli cells colonize and form tubules in murine hosts following transplantation and grafting procedures. J Androl 29: 418-430. 